\title{
An experimental study of the bandwagon effect in conspicuous consumption
}

\author{
Matgorzata Niesiobędzka \\ Institute of Psychology, University of Gdansk, Gdansk, Poland
}

BACKGROUND

The phenomenon of conspicuous consumption is not new. Veblen $(1899,1994)$ described conspicuous consumption as expensive, luxury consumption, which provides evidence of wealth and status. In post-modern society the primary objects of consumption have become images and experience used by the middle class and the masses to demonstrate uniqueness or similarity with significant others. This paper focuses on the bandwagon effect in conspicuous consumption. In the study the bandwagon effect is treated as increased demand for luxury goods due to their popularity, especially among famous people.

\section{PARTICIPANTS AND PROCEDURE}

Three studies were carried out. The samples consisted of 60 teenagers, 76 female students and 73 students and postgraduate students. The concept of the aspirational group was induced through the advertisement of a luxury product with reference to famous people and by direct reference to the aspirational group. Three different methods to measure a propensity to conspicuous consumption were applied: the amount of money spent on the luxury product, the size of the luxury brand logo, and the doubling of the luxury brand logo.

\section{RESULTS}

The results show that the activation of the idea of the aspirational group enhances willingness to pay more for a luxury product, to double the luxury brand logo and the preference for a visible luxury brand logo at a tendency level.

\section{CONCLUSIONS}

The results experimentally supported the bandwagon effect within luxury conspicuous consumption previously established in correlative studies.

\section{KEY WORDS}

conspicuous consumption; the bandwagon effect; aspirational group; experiment

CORRESPONDING AUTHOR - Prof. Małgorzata Niesiobędzka, Institute of Psychology, University of Gdansk,

4 Bażyńskiego Str., 80-952 Gdansk, Poland, e-mail: psymn@ug.edu.pl

Authors' Contributions - A: Study design · B: Data collection · C: Statistical analysis · D: Data interpretation ·

E: Manuscript preparation · F: Literature search · G: Funds collection

TO CITE THIS ARTICLE - Niesiobędzka M. (2018). An experimental study of the bandwagon effect in conspicuous

consumption. Current Issues in Personality Psychology, 6(1), 26-33.

RECEIVED 14.01.2017 · REVIEWED 03.03.2017 • ACCEPTED 24.04.2017 • PUBLISHED 22.05.2017 


\section{BACKGROUND}

The global market of luxury goods has grown very quickly. The traditional luxury sector's value in 1985 was estimated to be around 20 billion dollars, but in 2010 its value had already reached 250 billion and is expected to reach 376 billion dollars by 2017 (Kastanakis \& Balabanis, 2012, 2014). This value may be even higher if estimates include various categories of premium products. New luxury markets include for example China, which is the number one market for Hennessy cognac and the world's second-largest market for fashionable clothing and leather goods (Zhan $\& \mathrm{He}, 2012)$. In the modern post-materialistic society luxury consumption is not limited to the privileged few, but has become more affordable to the middle class and masses (Chaudhuri \& Majumdar, 2006, 2010; Granot, Toya, Russell, \& Brashear-Alejandro, 2013). The democratization of luxury also allows teenagers to use luxury goods as a means of social distinction (Gil, Kwon, Good, \& Johnson, 2012). What is more, access to the luxury world is possible not only by buying goods but also by renting them (Yeoman, 2010).

The motives underlying buying or renting luxury goods are mainly social. Veblen $(1899,1994)$, in his theory of the leisure class, presented socially developed strategies for strengthening or improving social status, such as conspicuous leisure and conspicuous consumption. Both strategies are based on the idea of waste: conspicuous leisure relates to wasting time and conspicuous consumption to wasting money by purchasing very expensive, luxury products. The usefulness of these goods is less important than their distinctive function and the ability to locate their owners on the prestige ladder. Veblen explained the motives of conspicuous consumption entirely from the perspective of status. Individuals engage in conspicuous consumption due to the perceived social equilibrium between price and status. Expensive, luxury consumption operates as a means of status signaling, providing evidence of wealth and therefore status. Leibenstein (1950) extended the analysis of conspicuous consumption and to the prestige effect (Veblen effect) added a description of the snob effect and the bandwagon effect. Leibenstein (1950, p. 189) defines the bandwagon effect as "the extent to which the demand for a commodity is increased due to the fact that others are also consuming the same commodity" and the snob effect as "the extent to which the demand for a consumer good is decreased owing to the fact that others are also consuming the same commodity". All three effects - ostentation, snobbery, and the bandwagon effect - may be included among motivational factors based on interpersonal orientation. Vigneron and Johnson (1999) distinguish five types of motivation underlying the acquisition of luxury products, which are of a personal or social nature. Hedonism and perfectionism are personal motives. The former is connected with searching for pleasures in the consumption of goods and the latter with the desire to possess the highest quality goods. Besides affective and utilitarian benefits, personal motives also include symbolic benefits - goods are used to express the inner self (Coulter, Price, \& Feick, 2003; Hemetsberger, von Wallpach, \& Bauer, 2012; Putoni, 2001; Tsai, 2005; Vigneron \& Johnson, 1999, 2004; Wong \& Ahuvia, 1998). Ostentation, snobbery, and the bandwagon effect are social motives. Ostentation is a type of motivation described by Veblen connected to the demonstration of social status. The need to be unique underlines the snob effect and it is associated with the search for unusual, original, and unique products. The desire to be fashionable, and the need to be included within an aspirational group, expressed in the search for fashionable products used by significant others, are responsible for the bandwagon effect (Vigneron \& Johnson, 1999). These products should have primarily a high iconic or verbal visibility index (Heffetz, 2004), and be a signal of scarcity due to limited supply, not due to high demand (Gierl \& Huettl, 2010).

The majority of research devoted to the social orientation of conspicuous consumption focuses on status seeking (Amatulli, Guido, \& Nataraajan, 2015; Friehe \& Mechtel, 2014; Kaus, 2013; Kim \& Jang, 2014; Mazzocco, Rucker, Galinsky, \& Andreson, 2012; O'Cass \& McEwen, 2006; Ordabayeva \& Chandon, 2011; Rucker \& Galinsky, 2009; Saad \& Vongas, 2009; Truong, Simmons, McColl, \& Kitchen, 2008). Only a small number of studies have been designed to analyze conspicuous consumption from the point of view of other social motives, such as snobbery and the bandwagon effect (Kastanakis \& Balabanis, 2012, 2014). This article focuses on the bandwagon effect within conspicuous luxury consumption. Bandwagon consumption occurs when consumers buy certain categories of luxuries due to their popularity, especially among famous people, movie stars, and celebrities (Amaldoss \& Jain, 2005; Chaudhuri \& Majumdar, 2006, 2010; Kastanakis \& Balabanis, 2012, 2014; Leibenstein, 1950; Vigneron \& Johnson, 1999, 2004). Such products guarantee social approval because they signify success, fame, and membership within relevant status groups. Kastanakis and Balabanis $(2012,2014)$ have shown that the self-concept orientation regulates the snob effect and the bandwagon effect. People with a strong, independent self, who are prone to dissociating themselves from other consumers, prefer non-relational, individualistic snobbish patterns of consumption. Furthermore, the relationships between the independent self and the snob effect are mediated by the need for uniqueness. The stronger the anti-conformism and desire to mark one's distinctiveness, the greater is the snob effect. On the other hand, people with a strong dependent 
self, and those who emphasize their similarity to some other consumers, choose products that enjoy approval and recognition among members of these groups. The relationship between the dependent self and the bandwagon effect depends on the strength of one's susceptibility to normative influences. Customers with a dependent self and with a strong propensity to indulge the expectations of aspirational groups try to purchase products that are popular within the reference group (Kastanakis \& Balabanis, 2012, 2014). Similar results from Tsai, Yang and Liu (2013) demonstrate significant relationships between a consumer's need for uniqueness, their susceptibility to normative influence and the snob effect, and the bandwagon effect.

The purpose of this study was to analyze bandwagon consumption through several experimental approaches, because the previous studies were only of correlative nature. The study was intended to determine whether the activation of the aspirational reference group concept has an impact on a propensity to conspicuous luxury consumption. It was expected that the activation of an aspirational reference group would enhance the propensity to conspicuous consumption. The aspirational reference group has a strong influence on luxury consumption due to conformity process, especially identification influence. Attitudes towards products, consumer choices made by non-membership desired groups are used by individual as a guide for their own attitudes and behavior. Contrary to normative influence, identification influence is not based on rewards or sanctions (Amaldoss \& Jain, 2005; Bearden \& Etzel, 1982; Bearden, Netemeyer, \& Teel, 1989; Deutsch \& Gerard, 1955; Grimm, Agrawal, \& Richardson, 1999; McGuire, 1968; Park \& Lessig, 1977; Zinkhan \& Lascu 1999). The symbolic meaning of products used by significant others helps individuals to construct, maintain, and express the desired identity. Therefore individuals choose products congruent with the social image of aspirational groups. Nowadays celebrities, such as movie and music stars, have become cultural icons. They serve as visible signs of wealth and fame - the values admired most by consumer society. The attempt to resemble the aspirational reference group underlies the bandwagon effect in conspicuous luxury consumption. Another form of social influence, other than identification with media figures, is one that activates constructs. People who want to be like celebrities are prone to adopt their attitudes and behavior, but not only those. The media figures activate mental constructs, including goals and norms (Lindenberg, Joly, \& Stapel, 2011). Media figures induce predominantly materialistic goals - wealth, fame and popularity. Luxury brands are socially recognized signs of wealth, and thus references to media figures via the activation of materialistic goals might enhance the willingness to purchase and display the luxury brand (conspicuous consumption).
Luxury products are perceived as more psychologically distant than ordinary goods and they are associated with an abstract mental representation. Hansen and Wänke (2011) demonstrated that luxury products act as more distant objects and require more abstract language. Consumers use more abstract language when they think of luxury. Products described in an abstract manner are perceived as more luxurious than products described concretely. Furthermore, an abstract language is often used in advertisements for luxury products (Hansen \& Wänke, 2011). Construal Level Theory (Trope \& Liberman, 2000, 2003, 2010) proposes that psychological distance from an object enhances the propensity to construe a more abstract representation of it. Temporal, spatial, and social distance leads to more abstract, generalized representation of the objects as it is observed in the case of luxury products. The psychological distance of luxury connects with the exclusiveness and unfamiliarity with luxury goods. Well-known, wealthy people are socially distant, but on the other hand they are perceived as proximal to luxury, and thus may be treated as vehicles to world of luxury. Thus associations, the recommendation of a luxury product by modern significant others (movie stars, celebrities) should enhance consumer willingness to purchase and display the luxury brand.

In order to better understand the bandwagon effect within conspicuous luxury consumption, three experimental studies were conducted. In the study the bandwagon effect is treated as increased demand for luxury goods due to their popularity, especially among famous people. The concept of the aspirational group was induced through the advertisement of a luxury product with reference to consumer icons - "stars" (Experiment 1, Experiment 2) - and by direct references to famous people (Experiment 3). The amount of money spent on the luxury product (Experiment 1), the size of the luxury brand logo (Experiment 2, Experiment 3), and the doubling of the luxury brand logo (Experiment 2) were used as the indicators of the propensity to conspicuous consumption (see: Griskevicius et al., 2007; Lee \& Shrum, 2012; Tyler et al., 2012; Wang \& Griskevicius, 2014).

\section{STUDY 1}

The purpose of Study 1 was to establish whether an activation idea of the aspirational group through the advertisement has an impact on the willingness to pay more for the luxury product. It was expected that the amount of money spent on the luxury product would be higher in the group with activation of the idea of the aspirational group through the advertisement (experimental group) than in the group without activation of the idea of the aspirational group (control group). 


\section{PARTICIPANTS AND PROCEDURE}

\section{Participants}

Sixty teenagers (33 schoolgirls, 27 schoolboys, $M_{\text {age }}=$ $=18.23$ years, $S D=0.47)$ were randomly assigned to experimental $(n=30)$ or control conditions $(n=30)$.

\section{Procedure}

Ad frame. Participants were told the study was intended to examine consumers' evaluation of an advertisement. Participants received an advertisement for an iPhone. In the experimental condition participants saw a picture of the iPhone and read the slogan "All your favorite stars already have it, and you?" while those in the control condition only saw the picture of the iPhone (visible, publicly consumed brand of product indicated as luxury in pre-test studies conducted in the comparative group).

Manipulation check. After watching the advertisement, participants were asked to complete a missing letter in a word. Two words were presented; each word could be completed in a different way, with one option referring to the world of famous people and the other option referring to a more neutral reference - without any association with famous people. The words to complete were the following: 1/ _ o d a (fashion/water, in Polish moda/woda); 2/ st_wa (fame/words; in Polish stawa/stowa).

Amount spent on luxury product. The participants reported the maximum amount of money they would spend to acquire the iPhone.

\section{RESULTS}

The $t$-test revealed a significant effect for manipulation $(t(58)=-2.41, p<.020)$. Participants in the experimental condition more often created words referring to the world of famous people (fashion and fame) $(M=1.03, S D=0.76)$ than participants in the control condition $(M=0.63, S D=0.49)$.

The $t$ test revealed a significant effect for the advertisement with the slogan referring to the favorite stars $(t(58)=-2.08, p<.040, d=.54)$. As predicted, participants watching the iPhone advertisement with the slogan were willing to pay significantly more $(M=1477.59 \mathrm{zl}, S D=962.47 \mathrm{zl})$ than participants watching the advertisement only with the picture of the iPhone $(M=988.17 \mathrm{zl}, S D=844.75 \mathrm{zl})$ (see Figure 1).

Consistent with the hypothesis, when the advertisement included references to the aspirational group, participants were willing to pay more for the luxury product than participants who watched the advertisement without explicit cues to significant others.

\section{STUDY 2}

The purpose of Study 2 was to establish whether activation of the idea of the aspirational group through the advertisement has an impact on the propensity to display a luxury brand logo. It was expected that the average size of a luxury brand logo would be larger in the group with activation of the idea of the aspirational group through the advertisement (experimental group) than in the group without activation of the idea of the aspirational group (control group). Furthermore, it was expected that the luxury brand logo would be doubled more often in the experimental group than in the control group.

\section{PARTICIPANTS AND PROCEDURE}

\section{Participants}

Seventy-six female students $\left(M_{\text {age }}=23.40\right.$ years, $S D=1.40)$ were randomly assigned to experimental $(n=40)$ or control conditions $(n=36)$.

\section{Procedure}

Participants were asked to solve three tasks. The first task was similar to the Stroop test. Participants saw the name of a color on the screen and were asked to write it in the frame below (there was a discrepancy between the color name and the font of the color). In the second task, participants had to link together the different lines. In the third task, participants had to count all the squares within a picture. From the beginning of the first task until the end of the third task, the right side of the screen contained a dynamic advertisement for "stax" headphones. The product and brand were not chosen at random. The target customers were women and men. The product had not yet

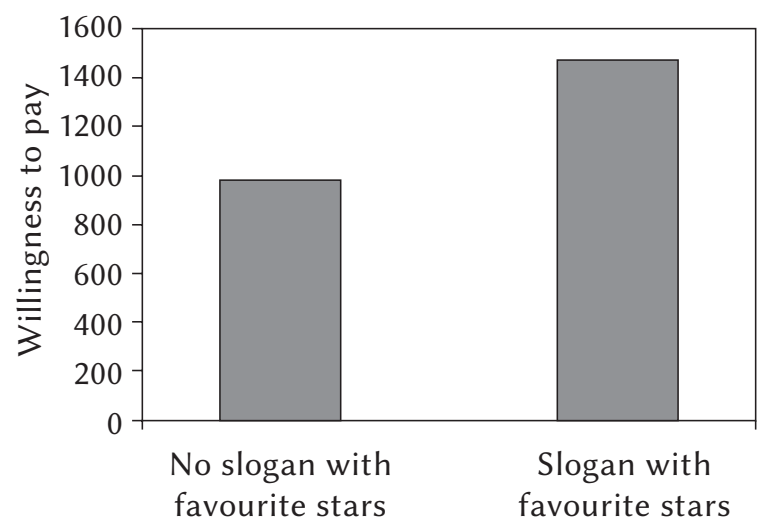

Figure 1. The amount of money spent on luxury product in the group with references to aspirational group and in the group without references to aspirational group. 
been advertised, and thus participants did not have any associations with the logo. In the experimental group and the control group, the formal features of the advertisement were the same; the differences concerned the content of the ad. The experimental group saw a picture of the headphones, the brand name "stax", and the slogan "Feel like a movie star". The control group only saw the picture of the headphones and the "stax" brand name.

Manipulation check. After completing the third task, respondents were asked to fill in gaps in the words. Two words were presented, with each presenting the possibility of being completed in a different way - one option referring to famous people and one option being neutral. The words to complete were the following: 1/ sz a $m p_{-} n$ (champagne/shampoo; in Polish szampan/szampon), 2/ st $t_{-} w a$ (fame/ words; in Polish stawa/stowa). It is important to note that after completing the third task, the advertisement did not appear.

Logo size. Participants were supposed to create a T-shirt they would like to wear. Respondents could change the view of the front and back of their T-shirt. They could change the shirt's color and could also include the Yves Saint Laurent logo, the size of which was also alterable. The default color of the T-shirt was gray with the colors to choose from blue, yellow to green. The default size of the logo was $140 \times 140 \mathrm{px}$, with a $40 \times 40 \mathrm{px}$ minimum and maximum of $450 \times$ 450 px.

Doubling of the logo. The Yves Saint Laurent logo could be placed both on the front and on the back of the T-shirt.

\section{RESULTS}

The $t$-test revealed a significant effect for manipulation $(t(65)=-5.77, p<.001)$. Participants in the experimental condition more often created words referring to famous people (champagne and fame) $(M=1.58$, $S D=0.62)$ than participants in the control condition $(M=0.58, S D=0.77)$.

The $t$ test revealed an effect for activation of the concept of the aspirational group through the advertisement $(t(74)=-1.93, p<.060, d=-.44)$, but only at the tendency level. Respondents who in performing their tasks were accompanied by the advertisement with the slogan "Feel like a movie star" put a larger Yves Saint Laurent logo $(M=232.11, S D=139.53)$ than participants in the control group $(M=176.03$, $S D=112.97$ ). Furthermore, a significant effect for activation of the idea of the aspirational group through the advertisement was observed in the doubling of the logo $\left(\chi^{2}=6.36, p=.010\right)$. In the experimental group $(n=17)$ participants put the Yves Saint Laurent logo on the front and the back of their T-shirts twice as often as the control group $(n=8)$.

\section{STUDY 3}

The purpose of Study 3 was to establish whether the direct activation idea of the aspirational group has an impact on propensity to display a luxury brand logo. It was expected that participants with the an aspirational group activation (experimental group) would be more willing to choose a T-shirt with a larger Ralph Lauren logo than participants without the activation concept of an aspirational group (control group).

\section{PARTICIPANTS AND PROCEDURE}

\section{Participants}

Seventy-three students and postgraduate students (34 female, 39 male, $M_{\text {age }}=27.01$ years, $\left.S D=3.28\right)$ were randomly assigned to experimental $(n=36)$ or control conditions $(n=37)$.

\section{Procedure}

Participants were told the study would be similar to a game. They were asked to recognize a person/animal based on clues given to them. In the experimental group, the people to be recognized were wellknown and wealthy, including Beyoncé, Bill Gates, and Angelina Jolie. In the control group, the animals to be recognized were also easily identifiable: a lion, a dog, and a bee. Participants first read clues and tried to guess who (experimental)/what (control) it was. If the answer was incorrect, participants were given the next clue. There were four clues; the clues at the beginning were more difficult than the clues at the end. If the answer was correct, a picture of the person (or animal) was displayed on the computer screen, and the next session began for a different person (or animal). The pictures also appeared after the four clues were given. For example, the clues about Angelina Jolie included: "membership of the Council on Foreign Relations", and "has three of her own children and three adopted children"; the clues about the lion were: "it is a wild carnivore", and "the males have a mane".

Manipulation check. After recognizing the person/animal, participants were asked to complete the missing letter in a word. Three words were presented, each of which could be completed in a different way and referring to the financial success of famous people or with a neutral connotation, lacking associations with money. The words to complete were the following: $1 / k_{-} s$ a (loot/scythe, in Polish kasa/kosa); 2/ f_rs a (brass/farce, in Polish forsa/farsa); 3/ _ to to (gold/mug, in Polish złoto/btoto).

Logo size. Four pictures of T-shirts with the Ralph Lauren logo were presented, aimed at female or male customers depending on the participant's sex. The logo 
differed in size: $20,28,40,54 \mathrm{~mm}$. The participants reported which T-shirt they would choose.

\section{RESULTS}

The $t$-test revealed a significant effect for manipulation $(t(70)=-2.76, p<.010)$. Participants in the experimental condition more often created words referring to money (loot, brass, and gold) $(M=2.42, S D=0.60)$ than participants in the control condition $(M=1.92$, $S D=0.91)$.

The $t$-test revealed a significant effect for aspirational group activation $(t(70)=-2.02, p<.050 ; d=.47)$. As predicted, participants with the aspirational group activation were willing to choose a T-shirt with a bigger Ralph Lauren logo $(M=36.50, S D=15.01)$ than participants in the control group $(M=30.38$, $S D=10.51$ ) (see Figure 2). Consistent with the hypothesis, the activation of the aspirational group enhanced preferences for a clearly visible logo.

\section{DISCUSSION}

The purpose of this study was to analyze bandwagon consumption from several experimental approaches, due to the correlative nature of previous studies. Through three experiments, I am able to provide evidence that the activation of the aspirational reference group concept significantly affects the propensity to conspicuous consumption. Participants watching advertisements that included references to significant others were willing to pay more for a luxury product and doubled the luxury brand logo on created T-shirts more often than participants watching advertisements without explicit references to significant others. It was also observed that the ad with the slogan "Feel like a movie star" encouraged respondents to place a larger luxury brand logo than the ad without the slogan, but only at a tendency level. Furthermore, the activation of the idea of the aspirational group by direct reference to famous people, e.g. Beyoncé or Angelina Jolie, enhanced preferences for a clearly visible luxury logo. Participants with aspirational group activation chose a larger Ralph Lauren logo size than participants without an activation notion of an aspirational group. The results of the experiments presented herein demonstrate that the activation of the aspirational reference group concept might enhance the propensity to conspicuous consumption probably due to the conformity process, especially to identification influence. The symbolic meaning of products used by significant others helps individuals to construct, maintain, and express desired identity. Therefore individuals choose products congruent with the social image of aspirational groups - nowadays celebrities, such as movie and music stars.
The influence of media figures on conspicuous consumption also connects with the activation of goals and norms (Lindenberg, Joly, \& Stapel, 2011). The media figures enhance willingness to purchase and display the luxury brands via the activation of materialistic goals. Luxury brands are socially recognized and visible signs of wealth and fame - materialistic goals. Furthermore, luxury products are perceived as more psychologically distant than ordinary goods. The psychological distance of luxury connects with the exclusiveness and unfamiliarity with luxury goods. Well-known, wealthy people are socially distant, but on the other hand they are perceived as proximal to luxury, and thus may be treated as vehicles to world of luxury. In the study the activation of the idea of modern significant others enhances consumer willingness to purchase and display the luxury brand. To sum up, the results experimentally supported the bandwagon effect within luxury conspicuous consumption previously established in correlative studies (Kastanakis \& Balabanis, 2012, 2014; Kim \& Jang, 2014; Tsai, Yang, \& Liu, 2013).

The present study has some limitations. In Experiment 2, the study group included only women. The previous results demonstrated a greater male tendency for conspicuous consumption than females. Men showing off their spending may be treated as an evolutionary strategy for signal status, as a social signal directed at potential mates (Griskevicius et al., 2007; Lens, Driesman, Pandelaere, \& Janssens, 2012; Nelissen $\&$ Meijers, 2011). Thus, the replication of Experiment 2 in a group consisting of men should demonstrate the bandwagon effect to more of an extent.

Furthermore, an important issue concerns the logos of the luxury brands presented to participants. The logos were chosen in pre-test studies conducted in the comparative groups - Yves Saint Laurent in the female student group and Ralph Lauren in the post-graduate student group. Nerveless,

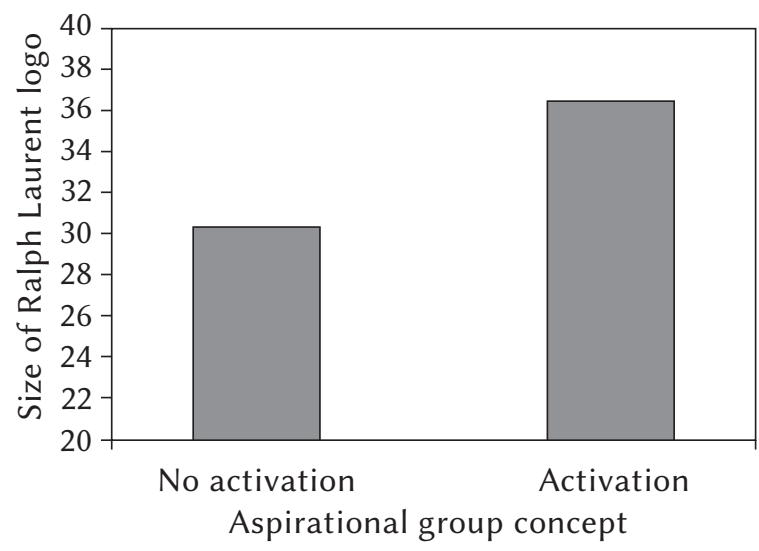

Figure 2. The size of luxury brand logo in the group with activation concept of aspirational group and in the group without activation concept of aspirational group. 
these brand logos might be perceived differently by participants; thus, in further studies the possibility of choosing a logo from some set of brands should be offered.

As was mentioned, only a small number of studies do not apply an entirely status-seeking perspective and attempt to explore other social motives of conspicuous consumption. Inclusion of the bandwagon effect and snob effect in the analysis allows us to better understand the complex nature of conspicuous consumption in post-modern society. The effect of the bandwagon effect on consumer behavior can be moderated by personality characteristics and situational influences. Therefore, future research should examine which personality traits and what situations might enhance the bandwagon effect within luxury consumption.

\section{REFERENCES}

Amaldoss, W., \& Jain, S. (2005). Conspicuous consumption and sophisticated thinking. Management Science, 51, 1449-1466. doi: 10.1287/mnsc. 1050.0399

Amatulli, C., Guido, G., \& Nataraajan, R. (2015). Luxury purchasing among older consumers: exploring inferences about cognitive age, status, and style motivations. Journal of Business Research, 68, 1945-1952. doi: 10.1016/j.jbusres.2015.01.004

Bearden, W. O., \& Etzel, M. J. (1982). Reference group influence on product and brand purchase decisions. Journal of Consumer Research, 9, 183-194.

Bearden, W. O., Netemeyer, R. G., \& Teel, J. E. (1989). Measurement of consumer susceptibility to interpersonal influence. Journal of Consumer Research, 15, 473-481.

Chaudhuri, H. R., \& Majumdar, S. (2006). Of diamonds and desires: understanding conspicuous consumption from a contemporary marketing perspective. Academy of Marketing Science Review, 11, 1-18.

Chaudhuri, H. R., \& Majumdar, S. (2010). Conspicuous consumption: Is That All Bad? Investigating the Alternative Paradigm. The Journal for Decision Makers, 35, 53-59.

Coulter, R. A., Price, L. L., \& Feick, L. (2003). Rethinking the origins of involvement and brand commitment. Journal of Consumer Research, 30, 151-182.

Deutsch, M., \& Gerard, H. B. (1955). A study of normative and informational social influenced upon individual judgment. Journal of Abnormal Social Psychology, 51, 624-636.

Friehe, T., \& Mechtel, M. (2014). Conspicuous Consumption and Political Regimes: Evidence from East and West Germany. European Economic Review, 67, 62-81. doi: 10.1016/j.euroecorev.2014.01.005

Gierl, H., \& Huettl, V. (2010). Are scarce products always more attractive? The interaction of different types of scarcity signals with products' suitability for conspicuous consumption. International Journal of Research in Marketing, 27, 225-235.

Gil, L. A., Kwon, K. N., Good, L. K., \& Johnson, L. W. (2012). Impact of self on attitudes toward luxury brands among teens. Journal of Business Research, 65, 1425-1433. doi: 10.1016/j.jbusres.2011.10.008

Granot, E., Toya, L., Russell, M., \& Brashear-Alejandro, T. G. (2013). Populence: Exploring Luxury for the Masses. Journal of Marketing Theory and Practice, 21, 31-44. doi: 10.2753/MTP1069-6679210102

Grimm, P. E., Agrawal, J., \& Richardson, P. S. (1999). Product Conspicuousness and Buying Motives as Determinants of Reference Group Influences. Advances in Consumer Research, 4, 97-103.

Griskevicius, V., Tybur, J. M., Sundie, J. M., Cialdini, R. B., Miller, G. F., Kenrick, D. T. (2007). Blatant Benevolence and Conspicuous Consumption: When Romantic Motives Elicit Strategic Costly Signals. Journal of Personality and Social Psychology, 93, 85-102. doi: 10.1037/0022-3514.93.1.85

Hansen, J., \& Wänke, M. (2011). The abstractness of luxury. Journal of Economic Psychology, 32, 789796. doi: 10.1016/j.joep.2011.05.005

Heffetz, O. (2004). Conspicuous Consumption and the Visibility of Consumer Expenditures. Working $\mathrm{Pa}-$ per, Princeton University. Retrieved from http:// forum.johnson.cornell.edu/faculty/heffetz/papers/conspicuous.pdf [access: 20.08.2014].

Hemetsberger, A., von Wallpach, S., \& Bauer, M. (2012). I'm Worth It' - Luxury and the Construction of Consumers' Selves. Advances in Consumer Research, 40, 483-489.

Kastanakis, M. N., \& Balabanis, G. (2012). Between the mass and the class: Antecedents of the "bandwagon" luxury consumption behavior. Journal of Business Research, 65, 1399-1407. doi: 10.1016/j. jbusres.2011.10.005

Kastanakis, M. N., \& Balabanis, G. (2014). Exploration variation in conspicuous luxury consumption: An individual differences' perspective. Journal of Business Research, 67, 2147-2154. doi: 10.1016/j. jbusres.2014.04.024

Kaus, W. (2013). Conspicuous consumption and "race": Evidence from South Africa. Journal of Development Economics, 100, 63-73. doi: 10.1016/j. jdeveco.2012.07.004

Kim, D., \& Jang, S. (2014). Motivational drivers for status consumption: A study of Generation Y consumers. International Journal of Hospitality Management, 38, 39-47. doi: 10.1016/j.ijhm.2013.12.003

Leibenstein, H. (1950). Bandwagon, Snob, and Veblen effects in the theory of consumers' demand. Quarterly Journal of Economics, 64, 183-207.

Lee, J., \& Shrum, J. (2012). Conspicuous Consumption versus Charitable Behavior in Response to Social Exclusion: A Differential Needs Explanation. Journal of Consumer Research, 39, 530-544. 
Lens, I., Driesman, S. K., Pandelaere, M., \& Janssens, K. (2012). Would male conspicuous consumption capture the female eye? Menstrual cycle effects on women's attention to status products. Journal of Experimental Social Psychology, 48, 346-349. doi: 10.1016/j.jesp.2011.06.004

Lindenberg, S., Joly, J. F., \& Stapel, D. A. (2011). The Norm-Activating Power of Celebrity: The Dynamics of Success and Influence. Social Psychology Quarterly, 74, 98-120. doi: 10.1177/0190272511398208

Mazzocco, P. J., Rucker, D. D., Galinsky, A. M., \& Andreson, E. T. (2012). Direct and vicarious conspicuous consumption: Identification with low-status groups increases the desire for high-status goods. Journal of Consumer Psychology, 22, 520-528. doi: 10.1016/j.jcps.2012.07.002

McGuire, W. J. (1968). Personality and Susceptibility to Social Influence. In O. P. John, R. W. Robins \& L. A. Pervin (Eds.), Handbook of Personality Theory and Research ( $3^{\text {rd }}$ ed.). New York: Guilford Press.

Nelissen, R. M. A., \& Meijers, M. H. C. (2011). Social benefits of luxury brands as costly signals of wealth and status. Evolution and Human Behavior, 32, 343355. doi: 10.1016/j.evolhumbehav.2010.12.002

O'Cass, A., \& McEwen, H. (2006). Exploring consumer status and conspicuous consumption. Journal of Consumer Behaviour, 4, 25-39. doi: 10.1002/cb.155

Ordabayeva, N., \& Chandon, P. (2011). Getting ahead of the Joneses: When equality increases conspicuous consumption among bottom-tier consumers. Journal of Consumer Research, 38, 27-41. doi: $10.1086 / 658165$

Park, C. W., \& Lessig, V. P. (1977). Students and housewives: Differences in susceptibility to reference group influence. Journal of Consumer Research, 4, 102-110.

Putoni, S. (2001). Self-identity and purchase intention: an extension of the theory of planned behavior. European Advances in Consumer Research, 5, 130-134.

Rucker, D. D., \& Galinsky, A. D. (2009). Conspicuous consumption versus utilitarian ideals: How different levels of power shape consumer behavior. Journal of Experimental Social Psychology, 45, 549555. doi: 10.1016/j.jesp.2009.01.005

Saad, G., \& Vongas, J. G. (2009). The effect of conspicuous consumption on men's testosterone levels. Organizational Behavior and Human Decision Processes, 110, 80-92. doi: 10.1016/j.obhdp.2009.06.001

Trope, Y., \& Liberman, N. (2000). Temporal construal and time - dependent changes in preference. Journal of Personality and Social Psychology, 79, 876-889. doi: 10.1037//0022-3514.79.6.876

Trope, Y., \& Liberman, N. (2003). Temporal construal. Psychological Review, 10, 403-421. doi: 10.1037/0033-295X.110.3.403

Trope, Y., \& Liberman, N. (2010). Construal-level theory of psychological distance. Psychological Review, 117, 440-463. doi: 10.1037/a0018963
Truong, Y., Simmons, G., McColl, R., \& Kitchen, P. J. (2008). Status and Conspicuousness - Are They Related? Strategic Marketing Implications for Luxury Brands. Journal of Strategic Marketing, 16, 189-203.

Tsai, W. S. (2005). Impact of personal orientation on luxury-brand purchase value. An international investigation. International Journal of Marker Research, 47, 429-454.

Tsai, W. S., Yang, Q., \& Liu, Y. (2013). Young Chinese Consumers' Snob and Bandwagon Luxury Consumption Preferences. Journal of International Consumer Marketing, 25, 290-304.

Tyler, F., Stillman, F., Fincham, D., Vohs, K. D., Lambert, N. L., \& Christa, A. P. (2012). The material and immaterial in conflict: Spirituality reduces conspicuous consumption. Journal of Economic Psychology, 33, 1-7.

Yeoman, I. (2010). The changing behaviours of luxury consumption. Journal of Revenue and Pricing Management, 10, 47-50. doi: 10.1057/rpm.2010.4

Veblen, T. (1899, 1994). The Theory of the Leisure Class. New York: Macmillan.

Vigneron, F., \& Johnson, L. W. (1999). A review and a conceptual framework of prestige-seeking consumer behavior. Academy of Marketing Science Review, 9, 1-14.

Vigneron, F., \& Johnson, L. W. (2004). Measuring perceptions of brand luxury. Journal of Brand Management, 11, 484-506. doi: 10.1057/palgrave. bm.2540194

Wang, Y., \& Griskevicius, V. (2014). Conspicuous Consumption, Relationships and Rivals: Women's Luxury Products as Signals to Other Women. Journal of Consumer Research, 40, 834-854. doi: 10.1086/673256

Wong, N. Y., \& Ahuvia, A. C. (1998). Personal taste and family face: luxury consumption in Confucian and Western societies. Psychology \& Marketing, 15, 423-432.

Zhan, L., \& He, Y. (2012). Understanding luxury consumption in China: Consumer perceptions of best-known brands. Journal of Business Research, 65, 1452-1460. doi: 10.1016/j.jbusres.2011.10.011

Zinkhan, G., \& Lascu, D. N. (1999). Consumer Conformity: Review, and Applications for Marketing Theory and Practice. Journal of Marketing Theory and Practice, 7, 1-12. 